\title{
The familiarity of idiopathic scoliosis: statistical analysis and clinical considerations
}

\author{
AG Aulisa1*, V Guzzanti', G Mastantuoni', M Giordano', A Poggiaroni', L Aulisa² \\ From 8th International Conference on Conservative Management of Spinal Deformities and SOSORT 2011 \\ Annual Meeting \\ Barcelona, Spain. 19-21 May 2011
}

\section{Background}

To our knowledge the aetiology of idiopathic scoliosis is still unknown. It is likely caused by the interaction of multiple factors rather than by the action of a single responsible. The fact that idiopathic scoliosis is often seen in members of the same family has led researchers to investigate the role of genetic factors in the aetiology of this disease $[1,2]$.

\section{Purpose of the study}

The purpose of this study was to evaluate the impact of the familiarity of idiopathic scoliosis in a selected family sample.

\section{Materials and methods}

The authors examined a family sample of 70 female patients with a relationship up to the third generation for a total of 2055 subjects. The parameters studied were: patient's age at first observation, the type of curve and the mother's and father's age at the patient's birth. The genealogy of the patients was investigated and related to the incidence of the disease.

\section{Results}

The outcomes showed that $73 \%$ of the patients had an age between 12 and 15 years and that the thoracic localization of the curves was the most frequent. The $60 \%$ of the mothers had an age between 20-29 years and 57\% of the patients were "first born". The $5.8 \%$ of the brothers and the $12.7 \%$ of the sisters were affected by scoliosis. From the analysis of the total sample it is clear that in $53 \%$ of the families there is at least another scoliotic besides the patient, while in the remaining $47 \%$ she was the only one affected.

${ }^{1}$ Children's Hospital Bambino Gesù, Rome, Italy

Full list of author information is available at the end of the article

\section{Conclusions}

The statistical analysis revealed three different types of transmission: multifactorial; autosomic dominant; autosomic recessive. Moreover female sex and firstborn resulted as risk factors of idiopathic scoliosis in the group of patients with multifactorial type of transmission.

\section{Author details \\ 'Children's Hospital Bambino Gesù, Rome, Italy. ${ }^{2 " A}$. Gemelli" Hospital, \\ Università Cattolica del Sacro Cuore, Italy.}

Published: 27 January 2012

\section{References}

1. Merolli A, Padua R, Pitta L, Aulisa AG, Ceccarelli E, Aulisa L: A statistical analysis of the familial incidence of Idiopathic Scoliosis. Stud Health Technol Inform 2002, 88:37.

2. Kouwenhoven JW, Castelein RM: The pathogenesis of adolescent idiopathic scoliosis: review of the literature. Spine (Phila Pa 1976) 2008 33(26):2898-2908.

\section{doi:10.1186/1748-7161-7-S1-073}

Cite this article as: Aulisa et al:: The familiarity of idiopathic scoliosis: statistical analysis and clinical considerations. Scoliosis 2012 7(Suppl 1): O73. and take full advantage of:

- Convenient online submission

- Thorough peer review

- No space constraints or color figure charges

- Immediate publication on acceptance

- Inclusion in PubMed, CAS, Scopus and Google Scholar

- Research which is freely available for redistribution 